\title{
Research on College Physical Education Reform Based on Humanization
}

\author{
Song Haiquan, Chen Hui \\ Guangzhou Huali Science and Technology Vocational College, Guangzhou, China, 511325
}

Keywords: College; Physical Education; Humanization

Abstract: With the continuous advancement of education and teaching reform in China, the reform of physical education in colleges and universities is also carried out in an orderly manner. All major colleges and universities are educating and cultivating the characteristics of each student on the basis of improving the overall quality of students. No longer a strange word. Various physical education and teaching methods around the "humanization" of college physical education reform have been used in real sports teaching, and are constantly developing.

\section{Introduction}

The humanization of college physical education reform with the influence of China's social development and the international environment, the exam-oriented education has been outdated, and the "humanization" teaching is going deep into all levels of schools, but its roots are the "humanized" teaching model. There is still a certain misunderstanding of the true use and true understanding of its meaning. Strengthening the understanding of the meaning of "humanization" will become a key issue in the reform of colleges and universities in China, and comprehensive and targeted understanding is of paramount importance.

\section{Understanding of "humanization"}

In terms of literal meaning, "humanization" is nothing more than respecting people, respecting each person's development, embodying care and love for humanity in all aspects, and promoting people's all-round development on the basis of respecting individuality. Then, for the education level, the "humanized" education model is to respect each student's personality, establish different teaching contents, teaching modes and teaching methods for each student, and apply different concepts and attitudes to respect student development. On the basis of respecting the development of personality, harmony and unity are achieved. In essence, the "humanized" education model achieves a degree of compatibility between the students' internal needs and the actual external conditions, enabling students to find a teaching model that conforms to their own development in various teaching modes. In short, the "humanization" teaching is a teaching method that fully gives students space and gives students a certain guide in a free environment. Comprehensive sustainable development is the "humanized" teaching ${ }^{[1]}$. 


\section{The disadvantages of the reform of physical education in colleges and universities in China}

From the current point of view, the reform of physical education in colleges and universities in China has achieved corresponding effects to a certain extent, both in terms of curriculum, teaching methods, and even teaching concepts. For example, in the setting of physical education teaching content in colleges and universities, it is no longer a single course content such as basketball, football, and badminton. When students take physical education courses, there is still a lot of space, such as Sanda, Taekwondo, and Tai Chi. Some colleges and universities also put some intellectual projects into the physical education curriculum. However, even so, due to the influence of traditional factors, China's "humanization" college physical education reform still has certain drawbacks, which needs attention ${ }^{[2]}$. The problems in teaching are shown in figure 1.

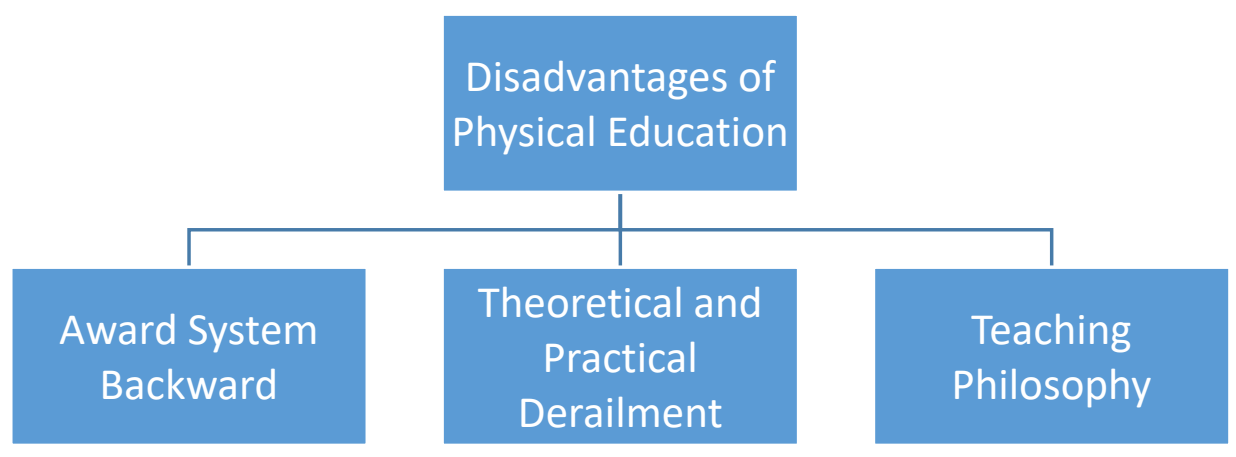

Figure 1 Problems in teaching

\subsection{The award system is backward}

Comprehensive evaluations are made from the students' learning status, thought state, learning style, learning content, and learning effects to help students and teachers improve in the next step of learning and teaching, thus forming a kind of relationship between teachers and students. Resonance, so that students and teachers develop together on the basis of mutual respect. However, at present, the award evaluation system that is compatible with the "humanized" teaching model has not yet appeared. The current award evaluation system is still limited to one aspect of the performance. It is obviously not in line with the humanity to use the results to evaluate the sports students. The requirements of the "teaching model" are even more hindering the specialties of sports students ${ }^{[3]}$.

\subsection{Theoretical and practical derailment}

Starting from the specific reality of sports students, because sports students and other students are different, their performance in a certain field of sports is very obvious. They need to play their individuality in the practice process and implement personalization into sports. In teaching, but in the current teacher-led environment, it takes a certain amount of time and space to apply the already relatively perfect "humanized" teaching theory to real teaching. To test the theory with practice is a truth that cannot be ignored. The "humanized" teaching theory and practice are not completely integrated and cannot be ignored ${ }^{[4]}$.

\subsection{The teaching philosophy of college physical education teachers needs to be improved}

From the current point of view, the overall quality of physical education teachers in colleges and universities in China needs to be improved. Their ability in physical education in a certain field 
cannot be ignored or even played a key role, but their comprehensive quality and cultural quality have not yet reached the requirements of "humanized" physical education reform are not even in line with the requirements of students' comprehensive development. Therefore, strengthening the "humanization" teaching concept of college physical education teachers is the key to the reform of college physical education.

\section{Achievements in the reform of physical education in colleges and universities in China}

First of all, in the teaching content, the reform of physical education has enriched the teaching content. For example, there are some track and field classes, gymnastics projects, and even traditional sports such as Sanda, Judo, and Tai Chi. As the needs of students increase, some intellectual programs also appear in the university's physical education classroom. Among them, there are more representative games of Go, Chess, Gomoku, and so on. Such colorful sports programs are active in college physical education classrooms, providing students with more choices and opportunities for choice, and they are able to more clearly guide the areas they are good at and the aspects they like.

Secondly, in terms of teaching thoughts, various advanced teaching ideas have been integrated into college physical education. Each university combines its own actual situation to improve the teaching philosophy of the university, which makes the school's physical education teaching concept more colorful.

Third, from the perspective of physical education methods, methods are diversified. Teachers systematically summarize and summarize according to different students and different teaching environments, trying to find a better way for college sports reform. The teaching method formed on this basis combines the advantages of various education and teaching modes. On the basis of accumulating experience, the teaching model is reformed and innovated, and more and better physical education teaching methods are obtained. It can be said that the reform of physical education under the guidance of the concept of "humanization" is a "win-win" state between teachers and students. Several aspects of the achievements of physical education reform in colleges in China are shown in the following figure 2.

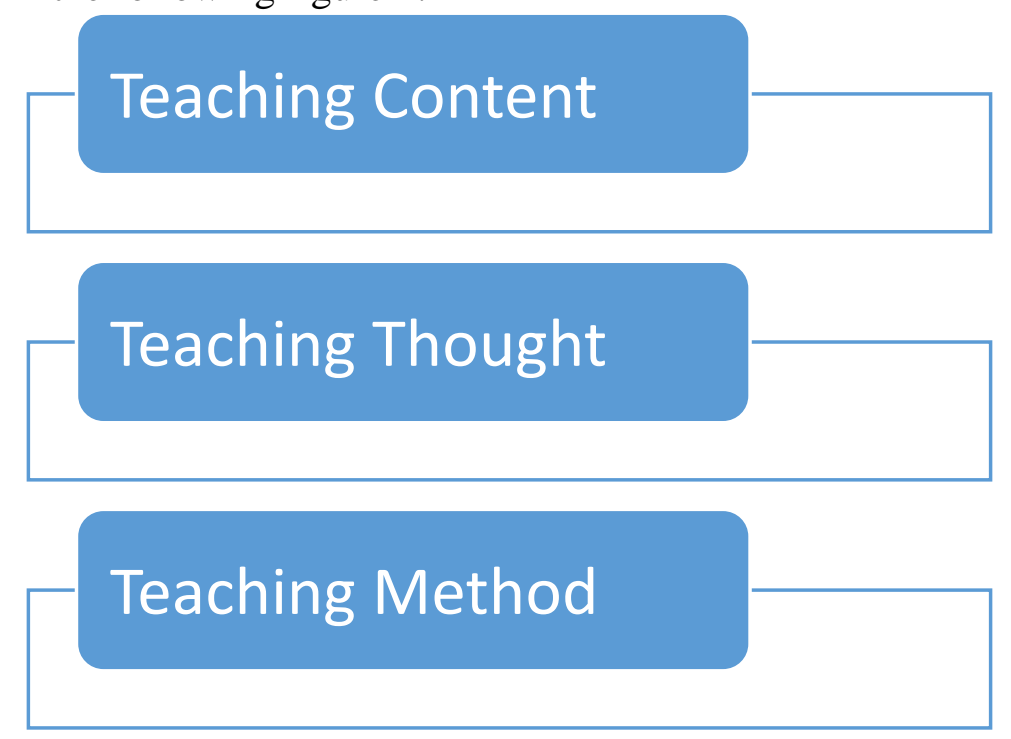

Figure 2 Several aspects of the achievements of physical education reform in colleges 


\section{The reform method of college physical education teaching from the perspective of "Humanization"}

No matter any kind of reform or development, it must be based on continuous problem solving and continuous innovation. The reform strategies and reform methods formed under such conditions will be more operable.

\subsection{Strengthening the reform of teaching ideas of college physical education teachers}

As the guide and important participant of physical education in colleges and universities, college physical education teachers only establish a mutual learning, mutual improvement and mutual learning between teachers and students based on the actual situation and the combination of their own teaching methods and individual quality differences. The relationship of communication, and through the sustainable development of this relationship, promote the reform of college physical education and achieve the goal of full respect. Therefore, in the reform of college physical education, teachers are a force that cannot be ignored. Their teaching concepts and teaching methods need to be constantly updated, and their comprehensive quality needs to be continuously enriched and improved.

\subsection{Establish an effective award system}

From the perspective of humanization, we must determine the evaluation system of colleges and universities under the guidance of the concept of publicity and respect for individuality, so that the award evaluation system plays a unique role in the development of personality, so that students can form good learning and living habits, and On the basis of their own quality, we will develop learning methods and learning concepts that are in line with our own quality, so as to create different learning effects in a certain teaching environment, so that college teaching mode can get rid of boring and boring, and appear in people with a new kind of attitude. Promote the sustainable development of students in the field of vision ${ }^{[5]}$.

\subsection{Practically introduce "humanization" into the teaching environment}

It is wrong to regard "humanization" as a stage of teaching reform or a component. To use it as a slogan to publicize it even more has lost the essence of college physical education reform. Therefore, it is necessary to introduce "humanization". In the practical environment of college physical education, "humanization" has become a guide for college physical education reform.

\section{Conclusion}

In summary, with the continuous reform of the humanistic reform mode of physical education teaching mode in colleges and universities in China, various teaching modes and teaching concepts that conform to individual development are eager to be active in college physical education. The teaching philosophy and teaching methods are also corresponding. The change, "respect" has become a center of college teaching reform, and on the basis of mutual respect is forming a "humanized" college physical education teaching model.

\section{References}

[1] Devon J. Hensel,Jennifer Nance,J. Dennis Fortenberry. The Association Between Sexual Health and Physical, Mental, and Social Health in Adolescent Women[J]. Journal of Adolescent Health,2016,59(4). 
[2] Kathleen A. Parks,Michael R. Frone,Mark Muraven,Carol Boyd. Nonmedical use of prescription drugs and related negative sexual events: Prevalence estimates and correlates in college students[J]. Addictive Behaviors,2017,65.

[3] Indra Neal Kar,Kaigang Li,Denise L. Haynie,Bruce G. Simons-Morton. Emerging adults without a driver's license engage in more transportation-related physical activity to school/work in certain environmental contexts[J]. Preventive Medicine,2017,96.

[4] Kirsten Corder,Stephen J. Sharp,Andrew J. Atkin,Lars B. Andersen,Greet Cardon,Angie Page,Rachel Davey,Anders Grøntved,Pedro C. Hallal,Kathleen F. Janz,Katarzyna Kordas,Susi Kriemler,Jardena J. Puder,Luis B. Sardinha,Ulf Ekelund,Esther M.F. van Sluijs. Age-related patterns of vigorous-intensity physical activity in youth: The International Children's Accelerometry Database[J]. Preventive Medicine Reports,2016,4.

[5] Gabriella M. Harari,Samuel D. Gosling,Rui Wang,Fanglin Chen,Zhenyu Chen,Andrew T. Campbell. Patterns of behavior change in students over an academic term: A preliminary study of activity and sociability behaviors using smartphone sensing methods [J]. Computers in Human Behavior,2017,67. 